\title{
COMPARING LABORATORY DYNAMIC MODULUS VALUES WITH LONG TERM PAVEMENT PERFORMANCE PREDICTIONS
}

\author{
A. S. M. Asifur RAHMAN, Rafiqul A. TAREFDER \\ Department of Civil Engineering, University of New Mexico, MSC01 1070, \\ Albuquerque, 87131-0001 New Mexico
}

Received 15 November 2013; accepted 04 September 2014

\begin{abstract}
This study compares laboratory dynamic modulus value of Superpave mixes with the dynamic modulus obtained from Long Term Pavement Performance (LTPP) database. The comparison shows that the dynamic modulus from LTPP database, which were determined by using different types of artificial neural network (ANN) models, differs from the laboratory tested dynamic modulus. The dynamic modulus data of five LTPP test sections are considered. Mixes similar to those five sections were collected from the field and tested in the laboratory. Based on the findings of this study, it can be said that dynamic modulus from ANN models are less than the laboratory dynamic modulus for New Mexico Superpave mixes. Therefore, as an important design parameter, the use of dynamic modulus predicted from Neural Network models can result in outcomes different from those using laboratory dynamic modulus.
\end{abstract}

Keywords: asphalt concrete, dynamic modulus, mastercurve, long term pavement performance, hot-mix asphalt, shift factor, asphalt binder, performance grade, Superpave mixes.

\section{Introduction}

Dynamic modulus $\left(\left|E^{*}\right|\right)$ is a key material property used in mechanistic empirical analysis of pavement to predict pavement distresses like rutting and cracking. It is also a very important parameter for the pavement thickness models. $\left|E^{\star}\right|$ is one of the two material properties that can be determined from complex modulus $\left(E^{\star \prime}\right)$ testing. The other property is the phase angle $(\phi)$, which is the difference between applied stress and measured strain response. The complex modulus $\left(E^{\star \prime}\right)$ is a complex number that relates stress to strain for a linear viscoelastic material subjected to sinusoidal loading. The absolute value of the complex modulus is commonly referred to as the dynamic modulus (1). In the case of asphalt concrete (AC), studying viscoelasticity by conducting dynamic modulus testing involves application of sinusoidal load as a function of frequency and temperature. The resulting strain is then mea- sured. In purely elastic materials, the stress and strain are in phase. In purely viscous materials, a 90-degree phase lag is expected. In viscoelastic material like asphalt, the behavior is somewhere in between that of purely elastic and purely viscous materials, exhibiting some phase lag less than that for purely viscous materials. In mathematical context, $\left|E^{*}\right|$ is the ratio of stress to recoverable strain (Meyers, Chawla 1999).

In Mechanistic Empirical Pavement Design Guide (MEPDG) (AASHTO 2008), the dynamic modulus is a necessary input along with the applied stress to determine tensile and compressive strains developed in a pavement structure. The tensile and compressive strains are then used in the MEPDG distress prediction models to evaluate rutting and fatigue cracking behavior of pavements. There are various methods available for the determination of $\left|E^{\star}\right|$ of hot-mix Asphalt (HMA). This study uses the current specification

Corresponding author:

A. Rahman E-mail: arahman@unm.edu 
for $\left|E^{*}\right|$ testing under uniaxial compression, according to the AASHTO T 342: "Standard Method of Test for Determining Dynamic Modulus of Hot-Mix Asphalt (HMA)" (AASHTO T 342: 2011).

The dynamic modulus is a fundamental property that defines the stiffness characteristics of hot-mix asphalt (HMA) mixtures as a function of loading rate and temperature. Therefore, $\left|E^{\star}\right|$ is an important input parameter of MEPDG. Currently, Long-Term Pavement Performance (LTPP) material test database does not include actual test results of $\left|E^{\star}\right|$. Rather LTPP includes dynamic modulus data predicted from different ANN models. The LTPP testing program was established before $\left|E^{*}\right|$ was identified as the main HMA property in the MEPDG (AASHTO 2008). Thus, actual test data of the LTPP sections considered for this study are not available. However, to run MEPDG using LTPP sections data, it requires the $\left|E^{*}\right|$ data.

The LTPP program developed several prediction models using artificial neural networks (ANN) to estimate the dynamic modulus of HMA mixes. These prediction models are: resilient Modulus $\left(M_{R}\right)$ based ANN model, viscosity based ANN model with or without viscosity from binder grade, and binder shear modulus $\left(G^{*}\right)$ based ANN model with or without consistent aging conditions (Kim et al. 2011). Researcher like Ceylan and et al. (Ceylan et al. 2008, 2009a, 2009b) worked on similar type of ANN models.

The ANN models developed by the LTPP program required an extensive independent data points obtained from laboratory testing. This database was compiled through the work at Arizona State University (Kim et al. 2011). The database was further combined with mix-properties database found from other national projects, including efforts undertaken at North Carolina State University. The Hot-Mix Asphalt (HMA) mix database that was used for ANN model development includes a total of 22,505 data points (Kim et al. 2011).

\section{Study approach}

In this study, Superpave HMA samples collected from different regions of New Mexico are tested in the laboratory for dynamic modulus $\left(\left|E^{*}\right|\right)$ in accordance to the standard specification provided by AASHTO T 342 . The $\left|E^{*}\right|$ versus reduced frequency $\left(f_{r}\right)$ mastercurves at $70{ }^{\circ} \mathrm{F}\left(21.1^{\circ} \mathrm{C}\right)$ generated from this study are compared to the mastercurves at same temperature generated for LTPP sections for the State of New Mexico.
The AASHTO PP 62: "Developing Dynamic Modulus Master Curves for Hot Mix Asphalt (HMA)" (AASHTO PP 62: 2009) specification was strictly followed while generating mastercurves for the HMA mix collected. A total of five LTPP sections throughout the state of New Mexico were considered for this study. The associated New Mexico Districts were identified for the LTPP sections. It was found that the LTPP sections considered in this study involve three of six New Mexico Department of Transportation (NMDOT) districts. A comprehensive HMA mix collection program was conducted with the associated districts to best represent New Mexico's LTPP mixes listed in the LTPP database. As the performance grade concept is a newer idea compared to the initiation of LTPP program, existing specification AASHTO MP 2: "Standard Specification for Superpave Volumetric Mix Design" (AASHTO MP 2: 2002) is used to approximate the Superpave gradation of the HMA materials documented in LTPP database.

\section{Test sections}

Table 1 presents the LTPP sections in New Mexico for which LTPP authority estimated the dynamic modulus of the HMA materials by various ANN models. The LTPP sections 0100, 0500, and 0800 fall in the region of New Mexico District 1. Section 1112 falls in District 2 and section 2007 is in District 5. Table 1 also lists the ANN Models used by the LTPP program to predict the dynamic modulus $\left(\left|E^{*}\right|\right)$ of different LTPP sections. For LTPP section 1112, the predicted estimate of dynamic modulus from viscosity based ANN model with viscosity from binder grade seemed to be erroneous. The LTPP test database for section 1112 listed the same value of dynamic modulus corresponding to all the standard specified temperatures (i.e. 14, 40 , 70,100 , and $130^{\circ} \mathrm{F}$ or $-10,4.4,21.1,37.8$, and $54^{\circ} \mathrm{C}$ ), which is impossible for asphaltic materials. Therefore, dynamic modulus output from the viscosity based ANN model with viscosity from binder grade had not considered in this study for the LTPP section 1112.

To identify the Superpave gradation for the LTPP samples, the gradation curves of these mixes are plotted in the Figure 1. According to the specification AASHTO MP 2 (AASHTO MP 2: 2002), all of the LTPP materials selected for this study fall more or less in the $19.0 \mathrm{~mm}$ Nominal Maximum Aggregate Size (NMAS) category. New Mexico's Superpave (SP) mix SP III gradation best represents these materials. 
Table 1. Selected LTPP sections and their physical locations

\begin{tabular}{|c|c|c|c|c|c|c|}
\hline $\begin{array}{l}\text { HMA } \\
\text { Sample }\end{array}$ & $\begin{array}{c}\text { SHRP } \\
\text { ID/ SPS } \\
\text { Project ID }\end{array}$ & Latitude & Longitude & Physical Location & $\begin{array}{l}\text { Prediction Model Used for Dynamic } \\
\text { Modulus Estimation }\end{array}$ & $\begin{array}{l}\text { New } \\
\text { Mexico } \\
\text { District }\end{array}$ \\
\hline \multirow{3}{*}{$\begin{array}{l}\text { Laboratory } \\
\text { Tested } \\
\text { Mix } 1\end{array}$} & 0100 & 32.67796 & -107.07014 & $\begin{array}{l}\text { On I-25 near } \\
\text { Rincon NM }\end{array}$ & $\begin{array}{l}\text { Resilient Modulus ANN, Viscosity ANN, } \\
\text { and Viscosity ANN with viscosity from } \\
\text { binder grade }\end{array}$ & 1 \\
\hline & 0500 & 32.19700 & -108.28208 & $\begin{array}{l}\text { On I-10 near NM } \\
146 \text { Intersection }\end{array}$ & Resilient Modulus ANN & 1 \\
\hline & 0800 & 32.19315 & -108.30111 & $\begin{array}{l}\text { I-10 Frontage } \\
\text { Road near NM } 146 \\
\text { Intersection }\end{array}$ & $\begin{array}{l}\text { Resilient Modulus ANN, Viscosity ANN, } \\
\text { and Viscosity ANN with viscosity from } \\
\text { binder grade }\end{array}$ & 1 \\
\hline $\begin{array}{l}\text { Laboratory } \\
\text { Tested } \\
\text { Mix } 2\end{array}$ & 1112 & 32.63344 & -103.51941 & $\begin{array}{l}\text { On West Carlsbad } \\
\text { near Hobbs, NM }\end{array}$ & $\begin{array}{l}\text { Resilient Modulus ANN, and Viscosity } \\
\text { ANN with viscosity from binder grade }\end{array}$ & 2 \\
\hline $\begin{array}{l}\text { Laboratory } \\
\text { Tested } \\
\text { Mix } 3\end{array}$ & 2007 & 36.24669 & -107.60322 & $\begin{array}{l}\text { On US } 550 \text { near } \\
\text { Cuba, NM }\end{array}$ & $\begin{array}{l}\text { Viscosity ANN with viscosity from } \\
\text { binder grade }\end{array}$ & 5 \\
\hline
\end{tabular}

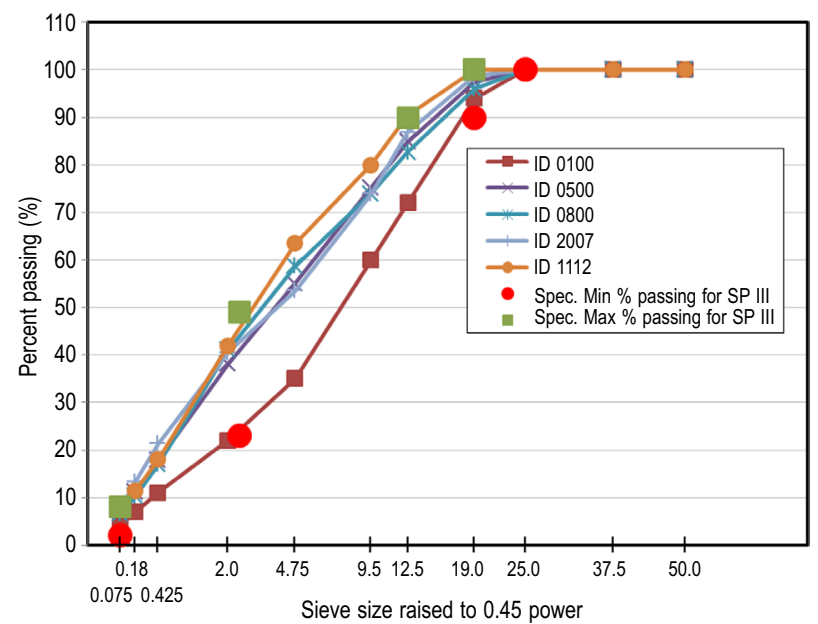

Fig. 1. Gradation curves for the HMA materials at LTPP sections.

Table 2 represents important material information at the selected LTPP sections considered for this study. This information was retrieved and gathered from the LTPP database. It was also used in the ANN models for predicting Dynamic Modulus. The information includes: Performance Grade (PG) of binder, the theoretical maximum specific gravity, bulk specific gravity, asphalt content and the air void.

\section{Mix collection}

To represent the HMA mixes used in New Mexico's LTPP sections, asphalt mixes were selected from different places of the state of New Mexico. The HMA mixes were primarily collected from the paving sites of on-going highway rehabilitation and reconstruction projects in cooperation with the NMDOT. Table 3 presents the summary of the plant mix HMA samples collected for this study.

The nominal maximum aggregate size of the samples collected in this study was $19 \mathrm{~mm}$ with SP III gradation according to AASHTO MP 2 (AASHTO MP 2: 2002). As shown in Figure 1, the aggregate gradations for the New Mexico's LTPP mixes fall more or less within $19 \mathrm{~mm}$ nominal maximum aggregate size gradation as per AASHTO MP 2 specification. Therefore, the aggregate gradations of the collected mixes can be considered to have aggregate gradations similar to those used in LTPP mixes. However, the binder performance grades for the collected HMA mixes differ from the mixes used in LTPP program. For example, for the LTPP section 0100, the estimated performance grade of the binder was found to be PG 64-22 (Table 2). On the other hand, the HMA mix collected from this region has a binder grade of PG 76-22 (Table 3). For this circumstance, it should be noted that the idea behind the Performance Grading was based on the fact that the binder properties for the HMA pavement under concern should be related to the climatic conditions under which the pavement operates (Kim 2009). Therefore, the on-going highway rehabilitation projects by the NMDOT in different districts considered this issue and used a binder suitable for the associated climatic region. 
Table 2. Information on the HMA materials at the selected LTPP sections

\begin{tabular}{|c|c|c|c|c|c|c|c|}
\hline $\begin{array}{c}\text { SHRP } \\
\text { ID/SPS } \\
\text { project } \\
\text { ID }\end{array}$ & $\begin{array}{c}\text { Nominal } \\
\text { maximum } \\
\text { aggregate } \\
\text { size }(\mathrm{mm})\end{array}$ & $\begin{array}{c}\text { Superpave } \\
\text { gradation } \\
\text { category }\end{array}$ & $\begin{array}{c}\text { Estimated performance } \\
\text { grade of the binder } \\
\text { from LTPP database, } \\
\text { used in the ANN } \\
\text { Model }\end{array}$ & $\begin{array}{c}\text { Average } \\
\text { bulk Sp. } \\
\text { gravity } \\
\left(G_{m b}\right)\end{array}$ & $\begin{array}{c}\text { Average } \\
\text { maximum Sp. } \\
\text { Gravity }\left(G_{m m}\right)\end{array}$ & $\begin{array}{c}\text { Air void (\%) in } \\
\text { the pavement } \\
\text { structure }\end{array}$ & $\begin{array}{c}\text { Average } \\
\text { asphalt } \\
\text { content }(\%)\end{array}$ \\
\hline 0100 & 19 & SP III & PG 64-22 & 2.2320 & 2.4087 & 7.34 & 3.50 \\
\hline 0500 & 19 & SP III & PG 64-22 & 2.2765 & 2.4095 & 5.52 & 5.26 \\
\hline 0800 & 19 & SP III & PG 64-22 & 2.0126 & 2.2107 & 8.96 & 7.00 \\
\hline 1112 & 19 & SP III & PG 64-22 & 2.4116 & 2.5770 & 6.42 & 5.05 \\
\hline 2007 & 19 & SP III & PG 64-22 & 2.2739 & 2.4455 & 7.02 & 4.67 \\
\hline
\end{tabular}

Table 3. Data summary of collected HMA samples

\begin{tabular}{|c|c|c|c|c|c|c|}
\hline $\begin{array}{c}\text { Serial } \\
\text { No. }\end{array}$ & $\begin{array}{c}\text { Date of } \\
\text { HMA sample } \\
\text { collection }\end{array}$ & $\begin{array}{c}\text { Nominal maximum } \\
\text { aggregate size }(\mathrm{mm})\end{array}$ & $\begin{array}{c}\text { Superpave } \\
\text { gradation } \\
\text { category }\end{array}$ & $\begin{array}{c}\text { Specified } \\
\text { performance grade } \\
\text { of the binder }\end{array}$ & $\begin{array}{c}\text { Physical location } \\
\text { of the project }\end{array}$ & $\begin{array}{c}\text { New mexico } \\
\text { district ID }\end{array}$ \\
\hline 1 & $8 / 13 / 2012$ & $19.0 \mathrm{~mm}$ & SP III & PG 76-22 & $\begin{array}{c}\text { I-25 Rehabilitation } \\
\text { Project, Sierra, NM }\end{array}$ & $\begin{array}{c}\text { US 82/NM 209 } \\
\text { Rehabilitation Project, } \\
\text { Lea, NM }\end{array}$ \\
\hline 2 & $10 / 22 / 2012$ & $19.0 \mathrm{~mm}$ & SP III & PG 70-22 & 2 \\
\hline 3 & $8 / 4 / 2011$ & $19.0 \mathrm{~mm}$ & SP III & PG 58-28 & $\begin{array}{c}\text { Various highways, Rio } \\
\text { Arriba, NM }\end{array}$ & 5 \\
\hline
\end{tabular}

Thus, the researchers of this study concluded that it would be more logical to compare the LTPP dynamic modulus data with the tested dynamic modulus for the collected mixes, although the LTPP and the collected mixes use different binder grades. This is also justifiable as because it would be impossible to find a HMA sample with binder grade, say PG 64-22 in a region where the climatic condition requires the binder grade to be PG 76-22. For all the LTPP sections considered for this study, the estimated binder grades are PG 64-22, which gives an indication that at the design period of this pavement sections, the climatic conditions was not considered. Therefore, at present it is not possible to find HMA sample with the binder grade similar to those used in the LTPP sections.

\section{Preparation of test specimens}

In the laboratory, the collected HMA mixes were heated to achieve the binder viscosity of $280 \pm 30$ centistokes (ASTM D 2493: 2009). Specifically, recommendations of compaction temperature by the binder suppliers' were used as for mix compaction temperature. The target air void of the compacted sample was set to $5.5 \pm 0.5 \%$ for consistency in test results. This range of air void also represents the average field condition for the pavements in the state of New Mexico. To reduce the number of trials for achieving target air void, three specimens were compacted at first and the density and air void were determined. A total of nine specimens (3 specimens for each of the New Mexico districts) were compacted using the Superpave gyratory compactor.

The specimens were compacted to a height of approximately $170 \mathrm{~mm}$ with $150 \mathrm{~mm}$ diameter. The specimens were then cored to obtain a $100 \mathrm{~mm}$ (4 in.) diameter test sample. Next, the test specimen was trimmed to the appropriate length by sawing approximately $12.5 \mathrm{~mm}(1 / 2 \mathrm{in}$.) from each end of the specimen. The average diameter, as per the AASHTO T 342 (3) requirements, was kept in between 100 and $104 \mathrm{~mm}$. Also, six measurements of the diameter at different location of the cylindrical specimen were taken into account to satisfy the diameter requirement by AASHTO T 342 (AASHTO T 342: 2011). The standard deviation, for the average of these six measurements recorded to the nearest $1.00 \mathrm{~mm}$, was less than $2.5 \mathrm{~mm}$. The average height of the cored and sawed samples at locations $120^{\circ}$ apart were kept in between 
147.5 and $152.5 \mathrm{~mm}$ as suggested by the standard. The required waviness requirement according to AASHTO T 342 for any sample was checked on three different axes which are $120^{\circ}$ apart. The maximum differential height across any diameter on these axes was taken as $0.05 \mathrm{~mm}$. This was accomplished by using a straight edge and feeler gauges. For the perpendicularity check, the specimen edge was kept within the permissible limit of $90^{\circ} \pm 1^{\circ}$ with the sample axis. This criterion was checked on three axes which are $120^{\circ}$ apart.

The material properties of the asphalt mixture were determined using AASHTO recommended standards. It includes the theoretical maximum specific gravity $\left(G_{m m}\right)$, air void, and bulk specific gravity $\left(G_{m b}\right)$. The theoretical maximum specific gravity $\left(G_{m m}\right)$ of loose mix was determined in accordance to the AASHTO T 209 (AASHTO T 209: 2007). AASHTO T 166 (AASHTO T 166: 2007) and AASHTO T 269 (AASHTO T 269: 2010) were used to determine the bulk specific gravity $\left(G_{m b}\right)$, and the percent air void $(A V \%)$ respectively. The asphalt content data was found from the individual mix design summary of the sample HMA mixes. Table 4 summarizes the theoretical maximum specific gravity for asphalt bound materials $\left(G_{m m}\right)$, the bulk specific gravity $\left(G_{m b}\right)$, percent air void $(A V \%)$, and the asphalt content $(A C \%)$ for each of the specimens prepared for this study. For the identification of the samples listed in Table 4, the first two numbers represent the serial number of the tested sample, and the last two alpha-numeric characters represent the New Mexico Department of Transportation's district ID.

Table 4. Summary of Maximum Specific Gravity, Asphalt Content, Bulk Specific Gravity and Percent Air Void for the collected HMA samples

\begin{tabular}{|c|c|c|c|c|}
\hline $\begin{array}{c}\text { Sample } \\
\text { ID }\end{array}$ & $\begin{array}{c}\text { Average theoretical } \\
\text { maximum specific } \\
\text { gravity }\left(G_{m m}\right)\end{array}$ & $\begin{array}{c}\text { Asphalt } \\
\text { content } \\
(\mathrm{AC} \%)\end{array}$ & $\begin{array}{c}\text { Bulk specific } \\
\text { gravity }\left(G_{m b}\right)\end{array}$ & $\begin{array}{c}\text { Percent } \\
\text { air void } \\
(\mathrm{AV} \%)\end{array}$ \\
\hline 01-D1 & 2.489 & 4.7 & 2.341 & 5.9 \\
\cline { 4 - 5 } 02-D1 & & & 2.339 & 6.0 \\
\hline 03-D1 & & & 2.345 & 5.8 \\
\hline 01-D2 & 2.471 & 4.5 & 2.342 & 5.2 \\
\hline 02-D2 & & & 2.347 & 5.0 \\
\hline 03-D2 & & & 2.334 & 5.5 \\
\hline 01-D5 & 2.488 & 4.6 & 2.348 & 5.4 \\
\hline 02-D5 & & & 2.353 & 5.6 \\
\hline 03-D5 & & & 2.351 & 5.1 \\
\hline
\end{tabular}

\section{Laboratory dynamic modulus testing}

The cylindrical asphalt concrete sample prepared were transferred to an environmental chamber and maintained at a set of testing temperatures: $14,40,70,100$, and $130^{\circ} \mathrm{F}\left(-10,4.4,21.1,37.8\right.$ and $\left.54^{\circ} \mathrm{C}\right)$ to conduct dynamic modulus testing. The specimens were tested using a sinusoidal loading at a set of specified frequencies: $25,10,5,1,0.5$, and $0.1 \mathrm{~Hz}$. The resulting strain and phase angles at each temperature and frequency combinations were recorded to calculate dynamic modulus.

For each of the temperature-frequency subset points, the amplitude of the cyclic stress was found by trials to keep the recoverable strain of the specimen to be limited in between 50 to 150 microstrains according to AASHTO T 342 (AASHTO T 342: 2011). The trial was done by assuming half of the cyclic load required to produce a recoverable strain of 28 to 30 microstrains. In this way, it was confirmed that when the full load is applied the specimen produces a recoverable strain with in this 50 to 150 microstrains. The cumulative sum of the permanent strains of all the frequencies at each temperature was kept below 1500 microstrains for each sample. This is specified by the standard to avoid excessive damage of the specimen. A set of Linear Variable Differential Transformers (LVDTs) were used to measure the deformation of the cylindrical HMA specimen under cyclic loading. The uniformity coefficient (UC-strain) for the strain measured by the LVDTs was kept within $35 \%$ and the uniformity coefficient for phase angle (UC-phase angle) measured by the LVDTs was kept less than $3^{\circ}$, as prescribed by the AASHTO T 342 standard (AASHTO T 342: 2011).

\section{Results and discussions}

For each of the HMA samples collected in this study, $\left|E^{*}\right|$ versus frequency mastercurves at $70^{\circ} \mathrm{F}\left(21.1^{\circ} \mathrm{C}\right)$ was determined to compare the results with LTPP dynamic modulus mastercurves at the same temperature. To facilitate a simpler representation of the comparison, the mastercurve plot for each individual New Mexico District was kept separated from the other districts. The following Eq. (1) was used to fit mastercurves (AASHTO PP 62: 2009):

$$
\log \left|E^{*}\right|=\delta+\frac{(\alpha)}{1+e^{\beta+\gamma\left[\log f+a_{1}\left(T_{R}-T\right)+a_{2}\left(T_{R}-T\right)^{2}\right]}},
$$


where $\alpha, \beta, \gamma, a_{1}$ and $a_{2}$ are the curve fitting parameters for the mastercurve, $f$ is the frequency of loading, $T_{R}$ is the reference temperature, and $T$ is any temperature other than the reference temperature. The reduced frequency $\left(f_{r}\right)$ is defined as:

$$
\log f_{r}=\log f+a_{1}\left(T_{r}-T\right)+a_{2}\left(T_{r}-T\right)^{2} .
$$

Table 5 represents the summary of mastercurve fitting parameters.

Table 5. Summary of mastercurve parameters for HMA mixes collected

\begin{tabular}{|c|c|c|c|c|c|c|}
\hline $\begin{array}{c}\text { New } \\
\text { Mexico } \\
\text { District ID }\end{array}$ & $\alpha$ & $\beta$ & $\delta$ & $\gamma$ & $a_{1}$ & $a_{2}$ \\
\hline District 1 & 2.7255 & -0.93 & 1.25 & -0.465 & 0.0765 & 0.00014 \\
\hline District 2 & 2.55 & -0.60 & 1.35 & -0.40 & 0.065 & 0.00011 \\
\hline District 5 & 3.1 & -0.65 & 0.82 & -0.40 & 0.061 & 0.00055 \\
\hline
\end{tabular}

For the LTPP dynamic modulus mastercurves it was necessary to mention the type of ANN model used to predict the dynamic moduli. LTPP used different types of ANN models to predict the Dynamic Modulus. Table 6 summarizes the parameters used to train the specific type of ANN model used by the LTPP program. Table 6 also summarizes the number of data points and node number used in the specific model.

Figures 2, 3 and 4 compare the mastercurves of laboratory mixes to the mastercurve obtained from LTPP sections for New Mexico District 1. LTPP Dy- namic Modulus mastercurves from different ANN models are kept separated from each other. Figure 2 compares the LTPP Dynamic Modulus mastercurve estimated using resilient modulus based ANN model $\left(\mathrm{M}_{\mathrm{R}}\right.$ model $)$ with laboratory tested dynamic modulus mastercurve. In a similar fashion, Figures 3 and 4 compare the laboratory tested dynamic modulus mastercurves with the LTPP predicted mastercurves from viscosity based (VV model) and viscosity based with viscosity from binder grade (VV-grade model) ANN models respectively.

In Figure 2, it can be seen that the resilient modulus ANN model used in LTPP program for the pre-

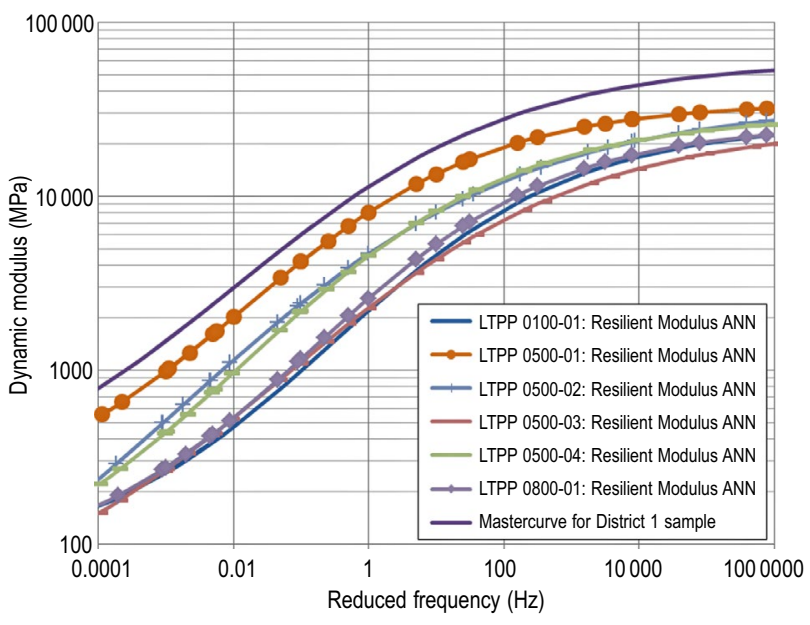

Fig. 2. Dynamic modulus mastercurves from laboratory tests and LTPP resilient modulus ANN model for New Mexico District 1

Table 6. Summary of parameters used to train LTPP ANN models

\begin{tabular}{|c|c|c|c|}
\hline ANN Model & Parameters used to Train ANN Model & $\begin{array}{l}\text { Number of data points } \\
\text { used to train } \\
\text { ANN model }\end{array}$ & $\begin{array}{l}\text { Number of nodes used } \\
\text { in the ANN model } \\
\text { (hidden and unhidden) }\end{array}$ \\
\hline $\begin{array}{l}\text { Resilient Modulus based } \\
\left(\mathrm{M}_{\mathrm{R}} \text {-model }\right)\end{array}$ & $\begin{array}{l}\text { Resilient modulus at } 5.25 \text { and } 40^{\circ} \mathrm{C} \\
\text { Shift Factors }\left(\alpha_{1}, \alpha_{2} \text {, and } \alpha_{3}\right)\end{array}$ & 11730 & 12 \\
\hline $\begin{array}{l}\text { Viscosity based model } \\
\text { (VV-model) }\end{array}$ & $\begin{array}{l}\text { Reduced Frequency } \\
\text { Viscosity } \\
\text { Voids in Mineral Aggregate (VMA) } \\
\text { Voids filled with Asphalt (VFA) }\end{array}$ & 14682 & 14 \\
\hline $\begin{array}{l}\mathrm{G}^{*} \text { based model } \\
(\mathrm{GV} \text {-model })\end{array}$ & $\begin{array}{l}\text { Voids in Mineral Aggregate (VMA) } \\
\text { Voids filled with Asphalt (VFA) } \\
\text { Binder shear modulus }\left(\mathrm{G}^{*}\right)\end{array}$ & 12907 & 12 \\
\hline $\begin{array}{l}\mathrm{G}^{\star} \text { based model with } \\
\text { consistent aging condition } \\
\text { (GV-PAR-model) }\end{array}$ & $\begin{array}{l}\text { Voids in Mineral Aggregate (VMA) } \\
\text { Voids filled with Asphalt (VFA) } \\
\text { Binder shear modulus }\left(\mathrm{G}^{*}\right)\end{array}$ & 12907 & 12 \\
\hline $\begin{array}{l}\text { Viscosity based model } \\
\text { with viscosity from binder } \\
\text { grade (VV-grade-model) }\end{array}$ & $\begin{array}{l}\text { Reduced Frequency } \\
\text { Viscosity } \\
\text { Voids in Mineral Aggregate (VMA) } \\
\text { Voids filled with Asphalt (VFA) }\end{array}$ & 14682 & 14 \\
\hline
\end{tabular}


diction of dynamic modulus under predicts the actual dynamic modulus found from laboratory tests for the New Mexico District 1. This was expected as because the HMA sample collected to represent the LTPP material has a stiffer binder grade of PG 76-22 compared to the estimated Performance Grade of the binder used in LTPP section of PG 64-22. For example, at a reduced frequency of $1 \mathrm{~Hz}$, a rough estimate of the average dynamic modulus by resilient modulus ANN model for all the LTPP sections can be considered to be around $4000 \mathrm{MPa}$, while the tested sample shows the modulus value to be above $12000 \mathrm{MPa}$. This difference seemed too high as because altering the actual binder with a stiffer one might not cause such a high difference in dynamic modulus values.

Similarly, for the entire reduced frequency domain, the high difference between the tested and the LTPP predicted dynamic modulus can be observed. The Viscosity ANN model used by LTPP program, in Figure 3, also under estimates the dynamic modulus values. In the lower frequency region (Fig. 3 ) the tested dynamic modulus values are about 5 to 6 times higher than the values predicted by LTPP Viscosity ANN model. In the higher frequency region this difference is about 2 times the predicted dynamic modulus by the ANN model. The Viscosity ANN with viscosity from binder grade model in Figure 4 also under predicts the dynamic modulus. The difference in this case is about 3 times the ANN predicted value at the lower frequency region, while about 2 times in higher frequency region. Certainly, the resilient modulus ANN model is under predicting the actual dynamic modulus in this case even though the tested sample has a stiffer binder grade.

Figure 5 compares the tested dynamic modulus mastercurves with the LTPP predicted mastercurves for the New Mexico District 2. For this region, the LTPP program only used the resilient modulus ANN model to predict the dynamic modulus. Also in this case, the ANN model used by the LTPP program for predicting dynamic modulus under predicts the actual dynamic modulus found from laboratory tests. This was also expected as because the laboratory tested sample has a stiffer binder grade. In this case the tested mix had a binder grade of PG 70-22, while the LTPP mix had an estimated binder grade of PG 64-22. At the lower frequency region the tested dynamic moduli are about 4 times higher than the prediction made by the LTPP resilient modulus ANN model. At the higher

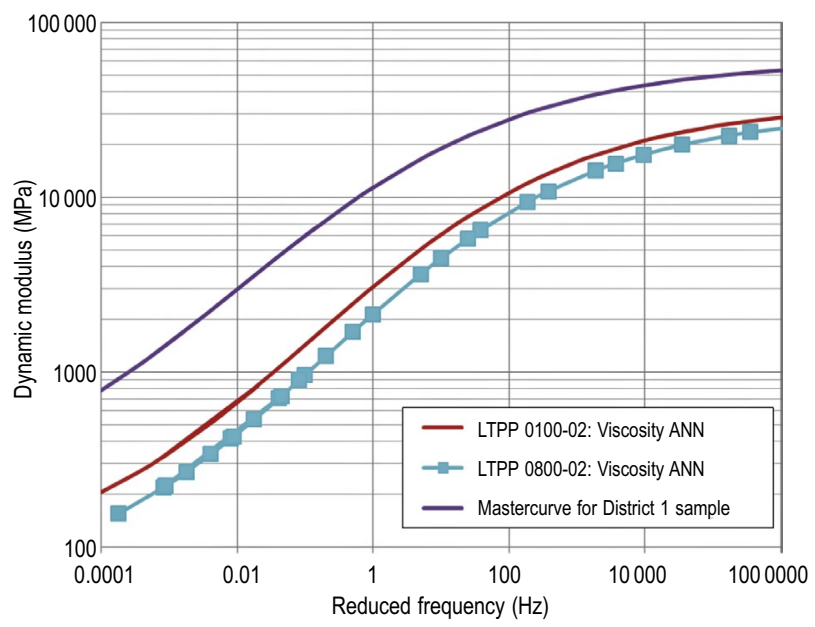

Fig. 3. Dynamic modulus mastercurves from laboratory tests and LTPP viscosity base ANN model for New Mexico District 1

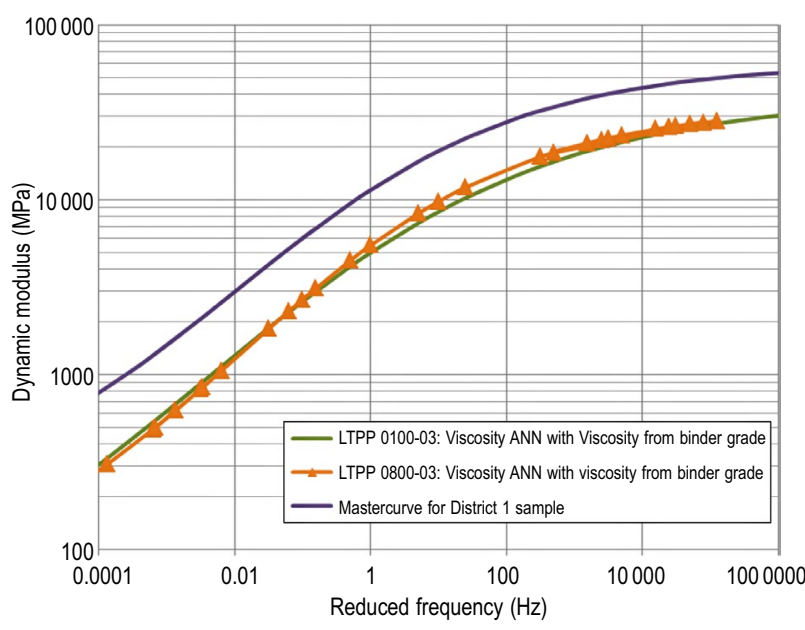

Fig. 4. Dynamic modulus mastercurves from laboratory tests and LTPP viscosity based ANN model with viscosity from binder grade for New Mexico District 1

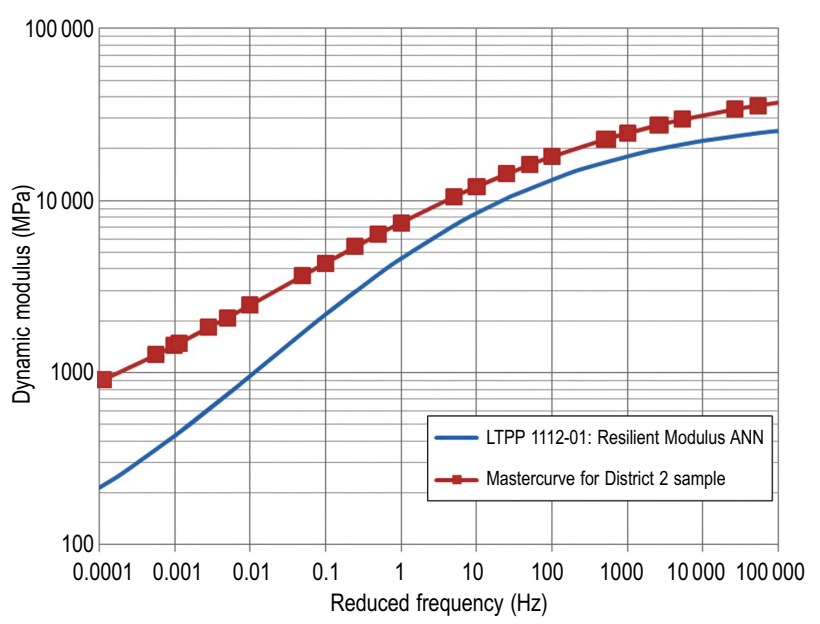

Fig. 5. Dynamic modulus mastercurves from laboratory tests and LTPP database for New Mexico District 2 
frequency region the tested modulus is about 1.5 times the modulus value predicted by the LTPP resilient modulus ANN model. Clearly, a Performance Grade alteration from PG 70-22 to PG 64-22 would not cause such a large difference in dynamic modulus values.

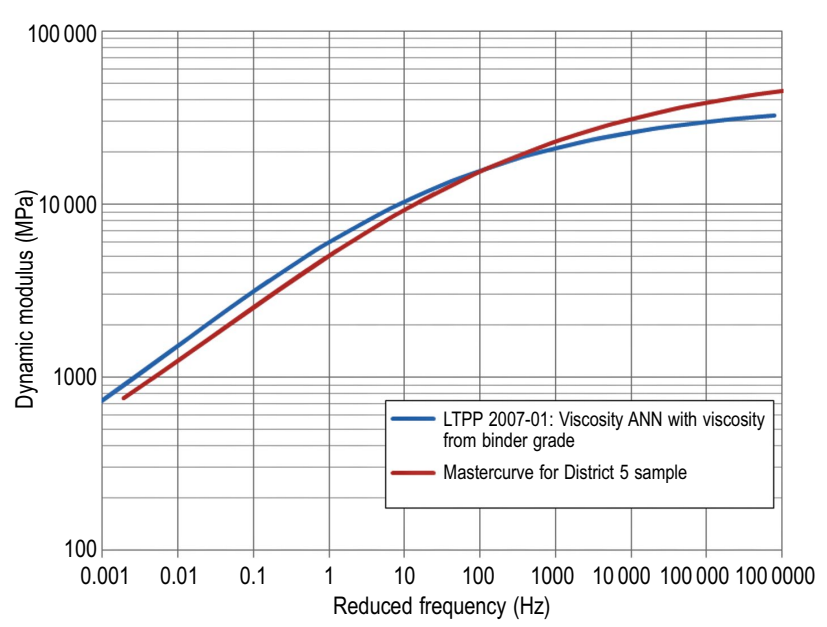

Fig. 6. Dynamic modulus mastercurves from laboratory tests and LTPP database for New Mexico District 5

Figure 6 represents the tested dynamic modulus mastercurves and the LTPP predicted mastercurves for the New Mexico District 5. For this region (New Mexico District 5), the LTPP program used the Viscosity based ANN model with viscosity from binder grade to predict dynamic modulus. In this case the tested sample has a binder grade of PG 58-28, while the LTPP section had an estimated binder grade of PG 64-22. The ANN model gives a fairly good prediction of dynamic modulus for District 5 at the low frequencies, as a little higher value were expected due to the less stiff binder in the tested mix. At high frequency, laboratory tested dynamic modulus values deviate from LTPP predicted values.

\section{Conclusions}

In this study, laboratory dynamic modulus $\left(\left|E^{\star}\right|\right)$ mastercurves are compared to the mastercurves obtained from the LTPP database for different regions in the state of New Mexico. LTPP dynamic modulus values were obtained from ANN models. The study shows that there is a considerable amount of under prediction of the dynamic modulus value by the ANN models used in LTPP program. It is therefore recommended not to use the LTPP dynamic modulus data as a design input for pavements in State of New Mexico.

\section{Acknowledgements}

Thanks to New Mexico Department of Transportation (NMDOT) for providing funding for this research project.

\section{References}

AASHTO. 2008. Mechanistic-empirical pavement design guide: a manual of Practice, AASHTO. Interim edition, July 2008. American Association of State Highway and Transportation Officials, Washington, DC.

AASHTO T 342: 2011. Determining dynamic modulus of hot-mix asphalt concrete mixtures. Standard specifications for transportation materials and methods of sampling and testing. American Association of State Highway and Transportation Officials, Washington, DC.

AASHTO PP 62: 2009. Standard practice for developing dynamic modulus master curves for Hot Mix Asphalt (HMA). Standard specifications for transportation materials and methods of sampling and testing. American Association of State Highway and Transportation Officials, Washington, DC.

AASHTO MP 2: 2002. Standard specification for superpave volumetric mix design. Provisional standards. American Association of State Highway and Transportation Officials, Washington, DC.

AASHTO T 209: 2007. Theoretical maximum specific gravity and density of hot mix paving mixtures, standard specifications for transportation materials and methods of sampling and testing, 27 $7^{\text {th }}$ ed., American Association of State Highway and Transportation Officials, Washington, DC.

AASHTO T 166: 2007. Bulk specific gravity of compacted hot mix asphalt using saturated surface-dry specimens. Standard specifications for transportation materials and methods of sampling and testing, $27^{\text {th }}$ ed. American Association of State Highway and Transportation Officials, Washington, DC.

AASHTO T 269: 2010. Percent air voids in compacted dense and open asphalt mixtures. Standard specifications for transportation materials and method of sampling and testing. American Association of State Highway and Transportation Officials, Washington, DC.

ASTM D 2493: 2009. Standard Viscosity-Temperature Chart for Asphalts, Construction Standards, ASTM International, West Conshohocken, PA.

Ceylan, H.; Gopalakrishnana, K.; Kim, S. 2008. Advanced approaches to hot-mix asphalt dynamic modulus prediction, Canadian Journal of Civil Engineering 35: 699-707. http://dx.doi.org/10.1139/L08-016

Ceylan, H.; Schwartz, C. S.; Gopalakrishnana, K. 2009a. Accuracy of predictive models for dynamic modulus of hotmix asphalt, Journal of Materials in Civil Engineering 21(6): 286-293.

http://dx.doi.org/10.1061/(ASCE)0899-1561(2009)21:6(286)

Ceylan, H.; Gopalakrishnana, K.; Kim, S. 2009b. Looking to the future: the next-generation hot mix asphalt dynamic modulus prediction models, International Journal of Pavement Engineering 10(5): 341-352.

http://dx.doi.org/10.1080/10298430802342690 
Kim, Y. R.; Underwood, B.; Far, M. S.; Jackson, N.; Puccinelli, J. 2011. LTPP computed parameter: Dynamic modulus technical report. Nichols Consulting Engineers, Chtd. Reno, NV.

Kim, R. Y. 2009. Modeling of asphalt concrete. American Society of Civil Engineers, Reston, VA.
Meyers, M. A.; Chawla, K. K. 1999. Mechanical behavior of materials. 2nd ed. Prentice Hall.

A. S. M. Asifur RAHMAN is a PhD student of the University of New Mexico. He received his Master of Science in engineering degree from University of New Mexico during the year 2012. His research interests are: construction materials, structural mechanics and computational modeling.

Rafiqul A. TAREFDER. PhD, P.E. Dr. Tarefder is an Associate Professor of Department of Civil Engineering, University of New Mexico. He received his doctorate degree from University of Oklahoma in 2003. His research interests are: characterization and modeling of asphalt materials, mechanistic pavement design, molecular dynamics, neural networks and nanoscale measurement of construction materials. 